University of Nebraska - Lincoln

DigitalCommons@University of Nebraska - Lincoln

1995

\title{
Inversion of a soil bidirectional reflectance model for use with vegetation reflectance models
}

\author{
Jeffrey L. Privette \\ University of Colorado \\ Ranga B. Myneni \\ Goddard Space Flight Center \\ William J. Emery \\ University of Colorado \\ Bernard Pinty \\ Dandy Randy University
}

Follow this and additional works at: https://digitalcommons.unl.edu/nasapub

Part of the Physical Sciences and Mathematics Commons

Privette, Jeffrey L.; Myneni, Ranga B.; Emery, William J.; and Pinty, Bernard, "Inversion of a soil bidirectional reflectance model for use with vegetation reflectance models" (1995). NASA Publications. 29.

https://digitalcommons.unl.edu/nasapub/29

This Article is brought to you for free and open access by the National Aeronautics and Space Administration at DigitalCommons@University of Nebraska - Lincoln. It has been accepted for inclusion in NASA Publications by an authorized administrator of DigitalCommons@University of Nebraska - Lincoln. 


\title{
Inversion of a soil bidirectional reflectance model for use with vegetation reflectance models
}

\author{
Jeffrey L. Privette, ${ }^{1}$ Ranga B. Myneni, ${ }^{2}$ William J. Emery, ${ }^{1}$ and Bernard Pinty ${ }^{3}$ \\ Abstract. The need for anisotropic soil reflectance in canopy reflectance modeling is assessed \\ for different sampling and canopy conditions. Based on the results for grasslands, a soil model is \\ inverted with ground-based radiometer data from the First International Satellite Land Surface \\ Climatology Project (ISLSCP) Field Experiment (FIFE). A general solution applicable over \\ different spectral bands, solar angles, and soil moisture levels is determined using a diverse data \\ set. With this solution, the model can be used as a lower boundary condition in FIFE canopy \\ modeling. Despite the previously reported independence of retrieved model parameters to data \\ sampling conditions, solutions determined with more limited data sets vary significantly. \\ Moreover, the semiphysically based model may not accurately predict reflectance in angular \\ regions where data are absent in the inversion process. These findings are important for the Earth \\ Observing System multiangle imaging spectroradiometer (MISR), which will gather data in \\ essentially one azimuthal plane per pass like the instrument used in this study did.
}

\section{Introduction}

Anisotropic reflectance has been observed over various soils including alkali flats, rocky deserts, and plowed fields. This anisotropy may be rather severe, exhibiting strong backscattering for rougher surfaces and strong forward scattering for smoother surfaces. In fact, the anisotropy in soil reflectance can exceed that of vegetation [Eaton and Dirnhirm, 1979].

Field studies have shown that soil reflectance anisotropy affects top-of-canopy (TOC) reflectance of thin canopies [Kimes et al., 1985a,b]. Despite the prevalence of sparsely vegetated land on the Earth's surface the inclusion of anisotropic soil boundaries in canopy reflectance models is far from universal. Indeed, most canopy models to date have either been of semiinfinite optical depth [e.g., Dickinson et al., 1990] or of finite depth with a Lambertian lower boundary [e.g., Verhoef, 1984]. Although the former approximation is reasonable for dense canopies, the suitability of a Lambertian approximation below thin canopies is doubtful. In fact, while many anisotropic soil models have been developed, the conditions requiring their use in vegetation models remain poorly defined. Moreover, the determination of a soil model under simulated remote sensing conditions has not been fully investigated. For example, soil parameters should ideally be determined from a small set of samples yet be applicable over all view angles, moisture levels, spectral bands and solar angles. Although practical issues may limit this determination, a realistic soil boundary is nevertheless necessary for the accurate use of canopy bidirectional reflectance distribution function (BRDF) models.

\footnotetext{
${ }^{1}$ Department of Aerospace Engineering Sciences, University of Colorado, Boulder.

${ }^{2}$ Biospheric Sciences Branch, NASA Goddard Space Flight Center, Greenbelt, Maryland.

${ }^{3}$ Laboratoire de Météorologie Physique, URA 267/CNRS Université Blaise Pascal, Aubière, France.

Copyright 1995 by the American Geophysical Union.

Paper number 95JD00851.

0148-0227/95/95JD-00851\$05.00
}

Prompted by the need to develop a reflectance model for a grassland, this study addresses these issues. After reviewing past work on coupled soil and vegetation scattering, the conditions under which soil anisotropy may be necessary are investigated. Next, a sensitivity study of soil model parameters is conducted to determine their impact on TOC reflectance. An inversion scheme to retrieve a generally applicable set of parameters from field reflectance data is then detailed and results are discussed. Finally, we attempt to validate the inversion solution for scattering directions absent of data during the inversion.

\section{Background}

Although the earliest canopy models assumed a semi-infinite optical depth [Ross, 1981], their generalization to finite depths required the specification of a lower-boundary condition. The simplest solution was a Lambertian reflector. The importance of specifying the Lambertian reflectance correctly was obvious given the characteristic differences in soil and vegetation spectra, particularly over the red and near-infrared (NIR) wavelengths. This fact was evident in attempts to model sparse canopy reflectance [Richardson et al., 1975; Rao et al., 1979].

Nevertheless, the anisotropy in soil reflectance is also well known [Irons et al., 1992]. The anisotropy has been modeled using empirical parameterizations [Walthall et al., 1985], Monte Carlo techniques [Cooper and Smith, 1985], and formulations based on the radiative transfer equation for semi-infinite media [Hapke, 1981; Pinty et al., 1989; Jacquemoud et al., 1992]. Others have attempted to model soil bidirectional reflectance using erect geometric shapes that cast shadows [e.g., Norman et al., 1985; Cierniewski, 1987]. Studies dedicated to the inversion of soil models include Pinty et al. [1989], Jacquemoud et al. [1992], and Irons et al. [1992].

The effects of soil anisotropy on TOC reflectance were initially investigated by Kimes and his colleagues [Kimes et al., 1980, 1985b; Kimes, 1983]. Kimes [1983] noted that sparse canopies $(<30 \%$ ground cover) show greater reflectance variability with changing solar zenith angles (SZAs) than do complete canopies. The reflectance of a sparse canopy is 
characterized by a strong backscatter peak in the retrosolar direction for low SZAs. This was attributed to the high gap probability at small SZAs and the strong backscatter of the comparatively bright soil at red wavelengths. The TOC reflectance decreases substantially with increasing view zenith angle (VZA) since the gap probability decreases. Kimes [1983] further noted that a sparse canopy behaves similarly to a complete canopy at high SZAs since the gap probability for the solar irradiance decreases. This reduces the impact of soil reflectance over all view angles. Soil effects are less noticeable in the NIR since soil reflectance is significantly lower than vegetation reflectance at these wavelengths.

The initial attempts to model a sparse canopy with anisotropic soil reflectance were by Kimes et al. [1985a]. This effort involved using a simple analytical model [Walthall et al., 1985] as the lower boundary of a ray-tracing canopy model [Kimes and Kirchner, 1982]. Through the systematic analysis of scattering components, Kimes et al. [1985a] were able to attribute net reflectance characteristics to underlying mechanisms. Similar relationships were reported by Cooper and Smith [1985], who used a Monte Carlo model with multiple scattering, and by Norman et al. [1985], who coupled the Cupid vegetation model to a simple, shadow-based soil model.

\section{Conditions Requiring Anisotropic Soil Reflectance}

Despite these efforts the conditions (spectral, angular, canopy) requiring anisotropic soil reflectance in canopy reflectance modeling have not been established. Below, we determine the errors in top-of-canopy reflectance when the soil is assumed to be Lambertian.

\subsection{Model Introduction}

The recent coupling of a numerical canopy reflectance model [Myneni et al., 1992] with an anisotropically reflecting soil model [Jacquemoud et al., 1992] presents an efficient tool with which thin/sparse canopy modeling can be advanced. DISORD is a turbid medium BRDF model based on the discrete ordinates solution to the radiative transfer equation [Myneni et $a l ., 1988$ ]. The model is three-dimensional, allowing variable properties in both the horizontal and the vertical directions. It models all known vegetation scattering phenomena and has been validated against several sets of field reflectance data. Further details may be found in the work of Myneni et al. [1992]. For the purposes of this study, DISORD was operated in one-dimensional mode (i.e., horizontal homogeneity was assumed).

Soil reflectance in DISORD may be treated as Lambertian or anisotropic. The anisotropic model [Jacquemoud et al., 1992] is a six-parameter extension of the Hapke model for planetary regoliths [Hapke, 1981]. The model uses two-term Legendre polynomials to approximate the backscatter $(b, c)$ and forward scatter $\left(b^{\prime}, c^{\prime}\right)$ regimes of the phase function. A roughness parameter $(h)$ allows increased reflectance in the retrosolar direction due to the absence of shaded surfaces along this view direction. The lone physical property is the soil single-scattering albedo $\left(\omega_{s}\right)$. This parameter varies with wavelength and soil moisture.

Throughout this study, reflectance values imply bidirectional reflectance factors (BRFs). Furthermore, a negative VZA denotes a backscatter direction, and a positive VZA de- notes a forward scatter direction. Half planes are illustrated for orthogonal plane reflectance since model results are symmetric in one-dimensional mode.

\subsection{Errors With a Lambertian Soil Assumption}

Previous studies [Goel and Thompson, 1984; Privette et al., 1994] have shown that canopy leaf area index (LAI) in part dictates the relative contributions of the soil and canopy to TOC reflectance. Studies suggest that soil reflectance becomes much less important as the canopy LAI exceeds about 3.0 [Kimes, 1983; Iaquinta and Pinty, 1994].

In this study, the effects of soil anisotropic reflectance were gauged at different LAI levels by comparing the TOC reflectance determined over Lambertian and anisotropic soil models. The anisotropic soil model was specified with parameter values obtained for a rough clayey soil [Jacquemoud et al., 1992]. The $\omega_{\mathrm{s}}$ values for slightly moist conditions were used. The SZA was set to $30^{\circ}$. The corresponding Lambertian feflectance was determined by a least squares fit of the anisotropic soil reflectance in 26 directions, evenly spaced, over the upper hemisphere. All canopy and irradiance parameters, excluding the varying LAI, were set to values encountered over a Kansas grassland [Sellers et al., 1988]. Although turbid medium models are not well suited for thin canopy conditions, low LAI values were included so that general trends would be obvious.

Errors in red TOC reflectance caused by Lambertian soil reflectance are shown in Figure 1. Most notable is the large reflectance deficit in the retrosolar direction. Strong backscattering (the hot spot) in true soil reflectance leads to this effect [Kimes, 1983]. Naturally, this effect is most pronounced at low LAI values and decreases as the canopy pathlength increases with LAI. Equally predictable is the overestimation of forward scattering since actual soil reflectance decreases markedly in the forward directions [Kimes, 1983]. These effects do not occur for some smooth soils [Jacquemoud et al., 1992]. Finally, the decrease in errors with increasing VZA (forward or backward) illustrates the effects of increasing pathlength on soil-reflected radiance.

Errors for NIR reflectance are similar (Figure 2). Although absolute errors in NIR are slightly larger than in red, they are

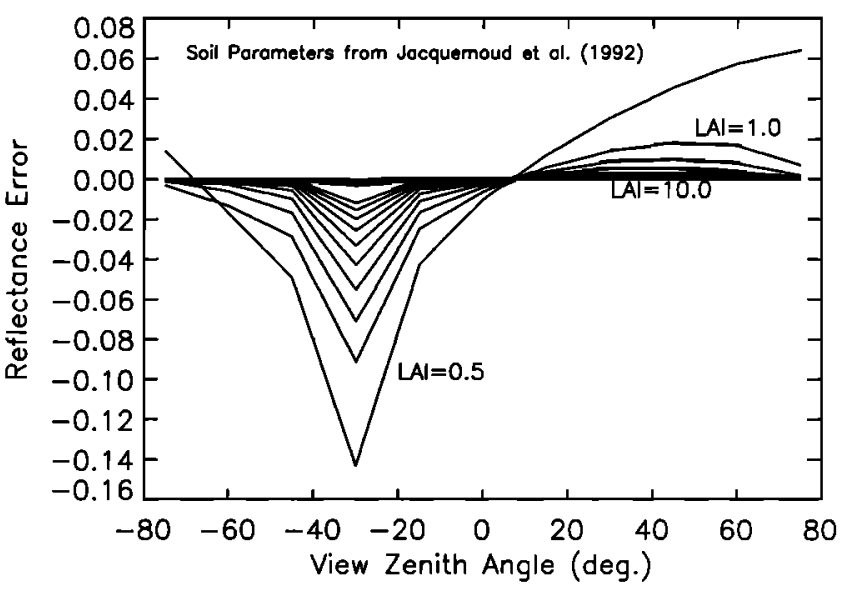

Figure 1. Error in top-of-canopy reflectance at red wavelengths due to a Lambertian (versus anisotropic) soil model. Leaf area index (LAI) increments are 0.5 for $0.5<\mathrm{LAI}<5.0$ and 2.5 for $5.0<\mathrm{LAI}<10.0$. The solar zenith angle (SZA) was $-30^{\circ}$. 


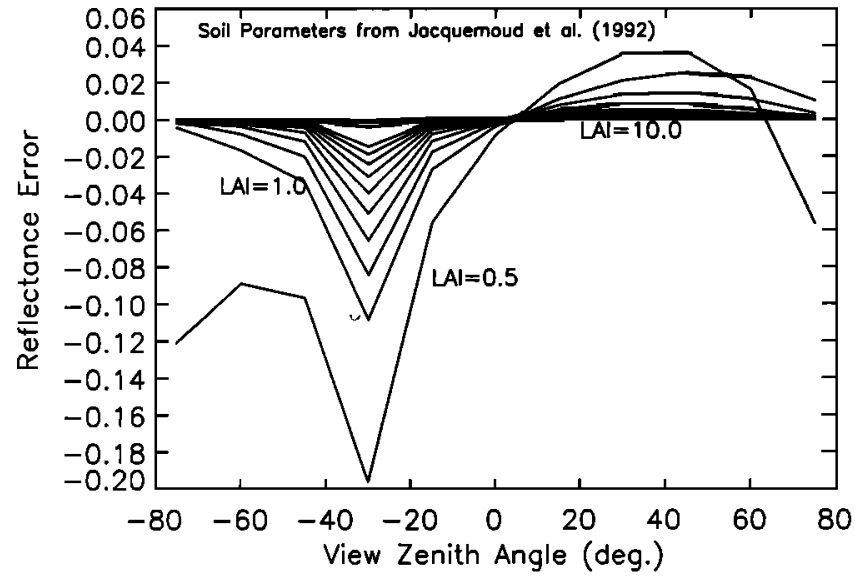

Figure 2. Same as Figure 1 but at near-infrared wavelengths.

significantly smaller relative to the canopy reflectance. This occurs since vegetation acts primarily as an absorber over relatively bright soil at red wavelengths, but vegetation is typically brighter than soil in the NIR. In addition, high multiple scattering in the canopy moderates the impact of soil reflectance anisotropy at NIR wavelengths.

\section{Determination of a Soil Boundary Condition}

In a separate paper [Privette et al., 1995] the inversion of DISORD with data gathered over grasslands is discussed. The determination of a suitable soil boundary condition for that investigation, given the results of section 3 , is presented here.

\subsection{FIFE Surface Description}

The First International Satellite Land Surface Climatology Project (ISLSCP) Field Experiment (FIFE) was a comprehensive study of a grassland climate and ecosystem in Kansas [Sellers et al., 1988]. The experiment included the coordinated measurement of soil, canopy and atmospheric properties via ground, aircraft, and space-borne detectors. Although most FIFE measurements were conducted in 1987 and 1989, only the 1989 (intensive field campaign 5) data were used here. Site 916 (4439-ECV), located near the center of the $15 \mathrm{~km} \mathrm{x} 15 \mathrm{~km}$ FIFE area, was chosen for this investigation. This choice was based on the relatively moist conditions, availability of extensive ancillary data, and comprehensive radiometric measurements. Site 916 underwent a prescribed burning in the spring of 1989 to eliminate dead vegetation from previous years. The site was not grazed or cultivated. The soil was of the Dwight series.

\subsection{Definition of the Inversion Problem}

To determine surface properties from reflectance data, model inversions are necessary. The inversion problem may be stated as follows: given a set of empirical directional reflectance values, determine the set of independent model parameters such that the modeled reflectance most closely resembles the measured reflectance. The merit function [Goel, 1988 ], $\varepsilon^{2}$, provides a numerical measure of this "resemblance," where

$$
\varepsilon^{2}=\sum_{j=1}^{n}\left[r_{j}-r_{j}^{*}\right]^{2}
$$

where $r_{j}$ is the directional reflectance for a given Sun-targetsensor geometry, $r_{j}^{*}$ is the geometrically analogous model estimate, and $n$ is the number of reflectance samples. Although equation (1) weights all directions equally, a variable weighting scheme may also be introduced.

\subsection{Sensitivity of Canopy Reflectance to Soil Parameters}

Destructive LAI measurements on August 8, 1989, indicated the mean green LAI at site 916 was about 1.94 (accounting for about $80 \%$ of the above-ground biomass). Thus according to Figures 1 and 2 an anisotropic soil reflectance model must be coupled to a canopy model to accurately simulate TOC reflectance.

Assuming a Lambertian soil, at least six canopy parameters may be successfully retrieved in a DISORD inversion [Privette et al., 1994]. However, the potential addition of six parameters for anisotropic soil reflectance meant DISORD would contain 11 adjustable parameters. To avoid overdetermination of the data, the parameter set was reduced. A previous study [Privette et al., 1994] suggested that model parameters producing the greatest change in TOC reflectance for small perturbations (analogous to the largest partial derivatives) are the same parameters that can be most accurately retrieved via model inversion. In contrast, parameters producing minimal changes may be fixed without significant loss of accuracy.

A sensitivity study of the simulated FIFE canopy was conducted to determine which, if any, of the soil model parameters may be fixed. Canopy reflectance at site 916 was simulated using measured parameter values [Privette et al., 1995]. Modeled reflectance compared favorably to measured values. A "baseline" TOC reflectance distribution was therefore computed using the clayey soil model [Jacquemoud et al., 1992] as a lower boundary. This reflectance was sampled at seven angles in the principal plane (see section 4.5). Next, each soil and canopy parameter was perturbed in turn by $10 \%$ of its imposed range, both positively and negatively. Parameter ranges were based either on theoretical or empirical information but generally defined reasonable limits under natural conditions. For each perturbation the sensitivity $(S)$ of the model to the perturbation was recorded, where

$$
\begin{gathered}
S=\frac{R M S}{\overline{r_{j}^{b}} \cdot 100} \\
R M S=\sqrt{\frac{\sum_{j=1}^{7}\left(r_{j}-\overline{r_{j}^{b}}\right)^{2}}{7}}
\end{gathered}
$$

and where $r_{j}^{b}$ is the baseline TOC reflectance in direction $j, r_{j}$ is the geometrically analogous reflectance of the perturbed distribution, and $r_{j}^{b}$ is the mean baseline reflectance. This exercise was repeated for three $\operatorname{SZAs}\left(30^{\circ}, 45^{\circ}\right.$ and $\left.60^{\circ}\right)$ and two wavelengths (red and NIR).

Sensitivity values for the soil parameters are shown in Tables 1 and 2. Results suggest that $\omega_{\mathrm{s}}$ produces the largest effects. This trend occurs at all solar angles and both wavelengths. The soil roughness and phase function parameters 
Table 1. Sensitivity of TOC Reflectance at Red Wavelengths to Perturbations in Soil Parameters

\begin{tabular}{lrrr}
\hline & \multicolumn{3}{c}{ Solar Zenith Angle, deg } \\
\cline { 2 - 4 } & 30 & 45 & 60 \\
\hline$\omega_{\mathrm{s}}$ & 13.652 & 10.234 & 5.356 \\
$\mathrm{~h}$ & 0.468 & 0.375 & 0.206 \\
$\mathrm{~b}$ & 7.911 & 5.825 & 3.262 \\
$\mathrm{c}$ & 6.825 & 5.187 & 3.125 \\
$\mathrm{~b}^{\prime}$ & 6.246 & 3.426 & 1.977 \\
$\mathrm{c}^{\prime}$ & 4.127 & 3.287 & 1.236 \\
\hline
\end{tabular}

TOC, top of canopy.

$\left\{h, b, c, b^{\prime}, c^{\prime}\right\}$ produce significantly smaller changes. Indeed, sensitivity values for these parameters were nearly always lower than those produced by the canopy parameters. Note that the greater impact of soil reflectance at red wavelengths, compared to NIR, is consistent with Figures 1 and 2.

\subsection{Invariance of Soil Roughness and Phase Function Parameters}

On the basis of the results above, the soil roughness and phase function parameters $\left\{h, b, c, b^{\prime}, c^{\prime}\right\}$ were chosen to be fixed for the DISORD inversions. However, the appropriate values with which to fix these parameters must be determined through inversion as they cannot be directly measured.

The roughness parameter has been related to the porosity of the medium. Thus after inversion the retrieved value should depend primarily on the soil type, not the sampling conditions (e.g., wavelength, geometries). The same may not be true for the phase function parameters. However, upon extensive inversion studies with laboratory reflectance data, Jacquemoud et al. [1992] concluded that the set $\left\{h, b, c, b^{\prime}, c^{\prime}\right\}$ is invariant for a given soil. These conclusions were not derived theoretically but were based on experimental evidence. Moreover, the parameter independence with soil moisture was invalid for smooth soils, particularly those with high clay content, since these soils exhibit a large specular effect near saturation but a decreased specular effect and increased backscatter with drying. For the purposes of this study, however, one set of soil parameter values that applies for all soil, canopy, and sampling conditions at site 916 was sought.

Table 2. Sensitivity of TOC Reflectance at NIR Wavelengths to Perturbations in Soil Parameters

\begin{tabular}{cccc}
\hline & \multicolumn{3}{c}{ Solar Zenith Angle, deg } \\
\cline { 2 - 4 } & 30 & 45 & 60 \\
\hline$\omega_{s}$ & 5.612 & 4.453 & 3.014 \\
h & 0.341 & 0.283 & 0.208 \\
b & 2.852 & 2.095 & 1.342 \\
c & 1.313 & 0.874 & 0.460 \\
b' & 2.475 & 1.663 & 1.054 \\
c' $^{\prime}$ & 0.795 & 0.531 & 0.018 \\
\hline
\end{tabular}

\subsection{Description of Empirical Reflectance Data}

Data from the Barnes model 12-1000 modular multiband radiometer (MMR) were used for the inversions. This choice was based on the availability of leaf optical data and independent soil and TOC reflectance data. The data were collected by a team from the University of Nebraska [Walter-Shea et al., 1992].

The MMR measured reflected radiation in seven bands in the shortwave spectrum $(0.45-0.52,0.52-0.60,0.63-0.69,0.76-$ $0.90,1.15-1.30,1.55-1.75$, and $2.08-2.35 \mu \mathrm{m}$ ). It had a $15^{\circ}$ instantaneous field of view (IFOV) and was mounted $3.5 \mathrm{~m}$ off the ground. A $3 \mathrm{~m} \times 3 \mathrm{~m}$ plot of bare soil was created by removing standing vegetation with a string trimmer. The root systems and stem stubble were left intact. During each measurement period the MMR sampled the plot at seven view angles in the principal plane (see Table 3). Typically, three samples were collected at each angle. In this study, all samples at a given angle were averaged. Since the instrument boom and housing occasionally shadowed the target area, the data were filtered such that contaminated samples were eliminated. The filter was based on the solar and view angles and was independent of the reflectance value.

Soil data from five days (July 26-28 and August 4 and 8, 1989) were used. Although bum residue covered the soil after the spring burning (F. Hall, personal communication, 1993), it was suggested the soil surface had reached a steady reflectance state by August (J. Norman, personal communication, 1993). Moisture data, obtained from gravimetric measurements in the top $5 \mathrm{~cm}$ of substrate, show two drying events over this period (see Figure 3 ). The average moisture decreased from $36 \%$ on July 26 to $26 \%$ on July 28 , and from $36 \%$ on August 4 to $25 \%$ on August 8 . To approximate beneath-canopy moisture conditions, the plot was covered with plastic mulch between measurement days. The mulch allowed the penetration of moisture but hindered the regrowth of vegetation. This mulch was removed in the moming before measurements began; however it was not, as a rule, replaced after each measurement. Thus the exposed soil was subject to accelerated drying during measurement days (B. Blad, personal communication, 1993).

\subsection{Accounting for Diffuse Irradiance in Soil Model}

As the reflectance data $\left(r_{j}\right)$ of Jacquemoud et al. [1992] were collected under laboratory conditions, there was no need to account for diffuse irradiance in the calculation of $r_{j}^{*}$. When compared to field data, however, $r_{j}^{*}$ should account for diffuse irradiance. If this correction is not included, the retrieved parameter sets would embody information on both the soil BRDF and the illumination conditions and hence not be atmospherically invariant.

Although natural diffuse irradiance is anisotropic, an isotropic parameterization was developed for this study. The scheme utilized an equally weighted quadrature procedure to determine the additional reflected component for each $r_{j}^{*}$. Because of its isotropic nature this parameterization depended only on the fraction of direct to total irradiance, $\gamma$.

The effect of diffuse irradiance on principal plane reflectance is shown in Figure 4 for a clayey soil. As $\gamma$ increases, the magnitude of the hot spot decreases due to the reduction in direct irradiance. Furthermore, scattering in the forward domain increases due to backscattering of diffuse irra- 
Table 3. Characteristics of Surface Reflectance Data

\begin{tabular}{|c|c|c|c|c|c|}
\hline Data Set & VZA, deg & $\begin{array}{l}\text { View Azimuth } \\
\text { Planes, deg }\end{array}$ & $\begin{array}{l}\text { Number of } \\
\text { Bands }\end{array}$ & SZA, deg & $\begin{array}{l}\text { Instrument } \\
\text { IFOV, deg }\end{array}$ \\
\hline $\begin{array}{l}\text { FIFE soil } \\
\text { plowed field } \\
\text { arid soils: }\end{array}$ & $\begin{array}{l}-50,-35,-20,0,20,35,50 \\
-75 \text { to } 75, \text { every } 15\end{array}$ & $\begin{array}{c}0 \\
0-135, \text { every } 45\end{array}$ & $\begin{array}{l}7 \\
2\end{array}$ & $\begin{array}{c}20-60 \\
26,30,45\end{array}$ & $\begin{array}{l}15 \\
12\end{array}$ \\
\hline $\begin{array}{l}\text { crust } \\
\text { dry sand } 1 \\
\text { dry sand } 2 \\
\text { gravel } \\
\text { wet sand }\end{array}$ & $\begin{array}{l}-48,-37,-25,-12,0,11,24,35,46 \\
\text { same } \\
\text { same } \\
\text { same } \\
\text { same }\end{array}$ & $\begin{array}{l}0,90 \\
\text { same } \\
\text { same } \\
\text { same } \\
\text { same }\end{array}$ & $\begin{array}{r}46 \\
\text { same } \\
\text { same } \\
\text { same } \\
\text { same }\end{array}$ & $\begin{array}{l}37,38 \\
28,27 \\
28,25 \\
24,23 \\
24,26\end{array}$ & $\begin{array}{l}15 \\
\text { same } \\
\text { same } \\
\text { same } \\
\text { same }\end{array}$ \\
\hline
\end{tabular}

VZA, view zenith angle; SZA, solar zenith angle; IFOV, instantaneous field of view.

diance. The general effect of increased diffuse irradiance is to make the surface reflectance more Lambertian. Indeed, if the direct stream is reduced to zero such that all irradiance is diffuse (as might exist on a cloudy day), the angular reflectance over the principal plane is nearly constant. These results are consistent with Irons et al. [1992], who used a geometrical optics soil model.

\subsection{Determining $\gamma$ From FIFE Data}

As $\gamma$ was not measured in MMR bands during FIFE, its value was estimated using the $5 \mathrm{~S}$ atmospheric model of Tanré et al. [1990]. To simulate actual conditions, the aerosol optical depth, water vapor, and column ozone were determined from FIFE data; a US62 thermodynamic profile and continental aerosol distribution were chosen from the 5S database. MMR band sensitivity was assumed uniform over the full band, halfpower (FBHP) bandwidths.

Simulations were conducted for 64 solar/atmospheric conditions per band corresponding to MMR measurement periods. Results in Figure $\boldsymbol{S}$ show that $\boldsymbol{\gamma}$ increases and its variability decreases with increasing wavelength. For inversion purposes this implies that spectrally independent parameters may be more accurately retrieved at longer wavelengths. Estimated $\gamma$ values were checked against values obtained with the PARABOLA radiometer [Deering et al., 1992] and were found to be consistent.

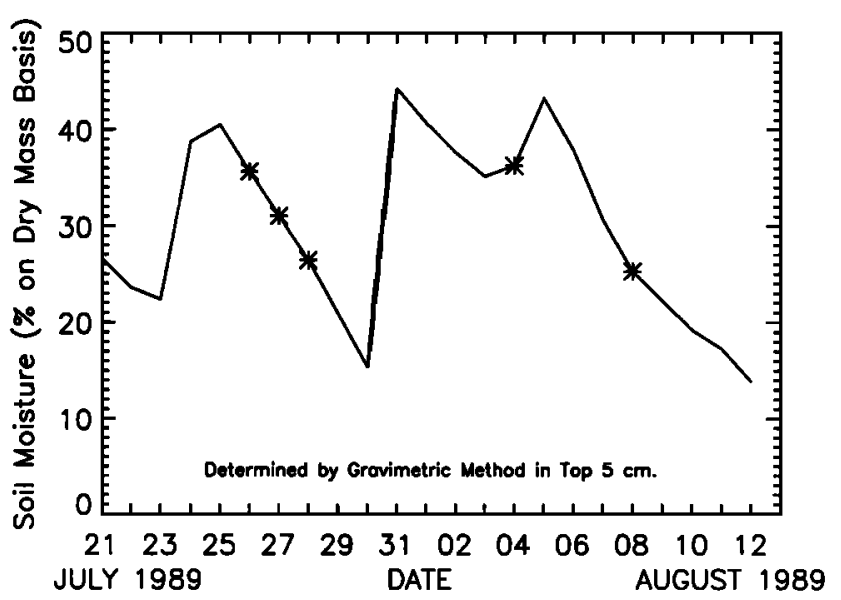

Figure 3. Variation of soil moisture at site 916 during intensive field campaign 5 . Asterisks indicate moisture levels for dates used in this study.

\subsection{Inversion Procedure}

The soil model was inverted by adjusting the set $\left\{\omega_{\mathrm{s}, 1}, \ldots\right.$, $\left.\omega_{\mathrm{s}, N}, h, b, c, b^{\prime}, c^{\prime}\right\}$, where $N$ represents the number of independent spectral and temporal data sets. The use of multiple values of $\omega_{\mathrm{s}}$ but single values of $h, b, c, b^{\prime}$, and $c^{\prime}$ reflects the reported spectral/moisture variance (invariance) of the respective parameters. The quasi-Newton algorithm E04JAF from the Numerical Algorithms Group (NAG) [1990] was used to minimize equation (1). This routine requires specification of initial parameter values. As there currently is no way to verify if and when optimization algorithms have found global minimizers (versus local minimizers), the starting position was prescribed randomly 50 times. One nonrandom initialization utilized the reported values for clayey soils [Jacquemoud et al., 1992]. The minimizer that resulted in the lowest merit function value (equation 1) was considered the global minimizer and recorded.

Although parameter constraints were not employed by Jacquemoud et al. [1992], they were necessary here to prevent errant results (e.g., negative reflectance values). The limits in Table 4 were established after a review of previous results [Jacquemoud et al., 1992] and some experimentation. Nevertheless, since the roughness and phase function parameters are not measurable properties, any limits on their values are somewhat arbitrary.

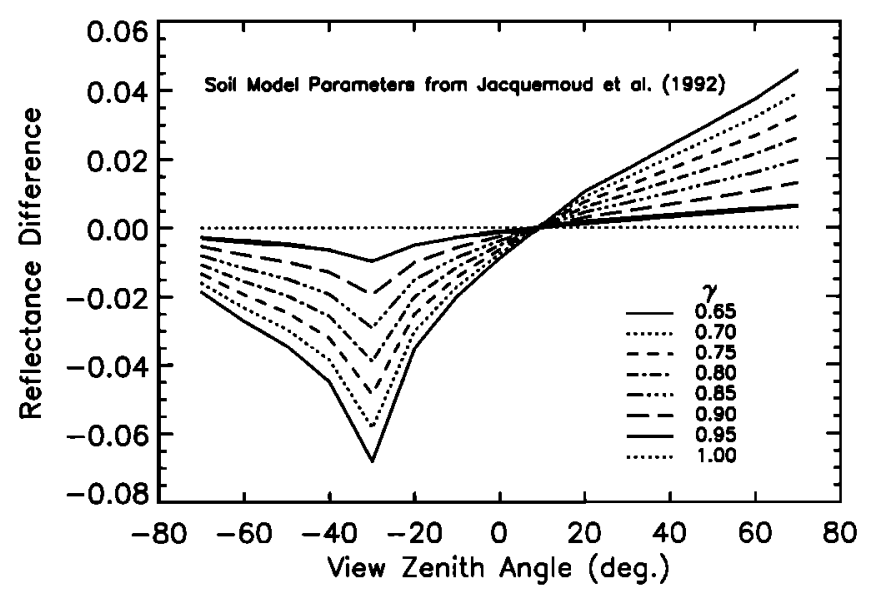

Figure 4. Change in principal plane reflectance of soil with $\gamma$ (ratio of direct to total irradiance). Ordinate values represent deviations from the reflectance for $100 \%$ direct irradiance (straight line). Diffuse irradiance was isotropic. The SZA was $-30^{\circ}$. 


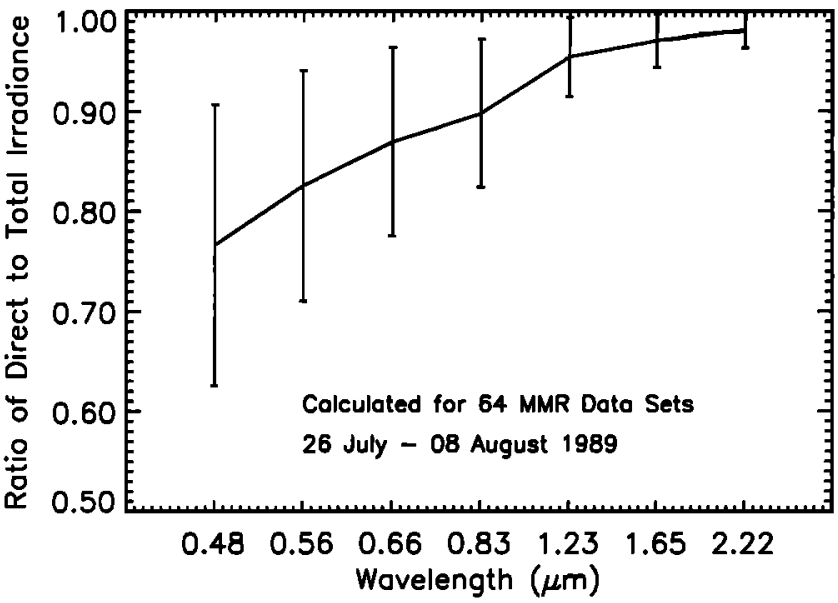

Figure 5. Means and standard deviations of $\gamma$ with wavelength for 64 measurement periods during intensive field campaign 5. Note values are given for the center wavelengths of modular multiband radiometer (MMR) bands. The abscissa scale is not linear.

\section{Results and Discussion}

Inversions were conducted in three configurations: (1) single bands at a single solar angle, (2) all seven bands together at a single solar angle (denoted "7BAND"), (3) and all bands and all solar angles together (denoted "ALLDATA"). For readability, inversions using the diffuse irradiance approximation are denoted "DIFF," while those without the approximation are denoted "NODIFF." The quality of the model fit is given by the RMS error,

$$
R M S=\frac{\varepsilon^{2}}{n-p},
$$

where $\varepsilon^{2}$ is the merit function value from equation (1), $n$ is the number of samples, and $p$ is the number of parameters adjusted in the inversion $(p=N+5)$. Note the values of $p$ and $n$ change according to the problem configuration.

\subsection{Inversions Using Single Bands}

Initially, the model was inverted separately with each MMR band at each solar angle. This condition required the determination of six parameters $(p)$ from seven reflectance samples $(n)$. Data sets with shadowed samples were excluded since nonlinear least squares problems (equation (1)) are not well determined when $n=p$. Thus for the five measurement days, only 10 of the 16 data sets were used.

Table 4. Parameter Constraints

\begin{tabular}{ccc}
\hline Parameter & Lower & Upper \\
\hline$\omega$ & 0.01 & 1.0 \\
h & 0.00 & 2.0 \\
b & -2.0 & 2.0 \\
c & -2.0 & 2.0 \\
b $^{\prime}$ & -2.0 & 2.0 \\
$c^{\prime}$ & -2.0 & 2.0 \\
\hline
\end{tabular}

First, the model was inverted using the diffuse irradiance approximation. The mean retrieved values and their standard deviations are shown in Table 5. Clearly, the mean parameter values are inconsistent over different bands. Also, the standard deviations are large with respect to the imposed parameter ranges (Table 4). Finally, the mean RMS errors are small. However, the combination of decreasing diffuse irradiance and increasing soil reflectance leads to greater reflectance anisotropy and hence larger RMS errors with increasing wavelength.

Next, the model was inverted without the diffuse irradiance approximation (Table 5). Although some parameters were more consistent over the different bands (e.g., $h$ and $b$ ), others remained inconsistent. Within-band inconsistency is again evident from the large standard deviations. The mean RMS values are the same as for the DIFF cases.

To assess the spectral independence of the solutions, those determined from band 7 inversions (DIFF and NODIFF) were used to fit band 1 data for the same solar angle. Presumably, soil reflectance behavior between these bands is less correlated than with other combinations since local spectral absorption peaks are produced by different molecules. In this comparison, the spectrally dependent $\omega_{\mathrm{s}}$ was readjusted for the best fit. The remaining five parameters remained fixed. Results are shown in Figure 6 for a low SZA (27.4 ) and low soil moisture $(26 \%)$ case. The hot spot is underestimated and the forward scattering is overestimated by both solutions. Errors are slightly worse for the DIFF solution. These results imply that for the given inversion configuration the retrieved solutions are spectrally dependent.

\subsection{Inversions Using All Bands (7BAND)}

To determine inversion solutions that were less spectrally dependent, we inverted the soil model with data from all seven MMR bands simultaneously (one solar angle). In this scenario, a single set of roughness and phase function parameters are adjusted with seven $\omega_{s}$ variables (one per MMR band). For the FIFE MMR data, 49 samples ( $n$ ) were fit with a 12-parameter $(p)$ model. All 16 data sets were used since the overdetermination of model parameters permitted the use of data sets missing samples due to shadow contamination.

Inversions with the diffuse approximation resulted in two nonconvergent cases. The mean results for the remaining 14 cases are shown in Table 5. The variance of the phase function parameters decreased markedly compared to the single-band results. In the NODIFF configuration, all 16 cases converged (Table 5). Although the variances are lower than for the single-band inversions, the values are generally larger than for the 7BAND DIFF case. The mean RMS error is the same as for the DIFF case.

To assess their dependence on SZA, the solutions (DIFF and NODIFF) for the data at SZA $=58.1^{\circ}$ (soil moisture $=36 \%$ ) were used to estimate the data obtained at $\mathrm{SZA}=27.4^{\circ}$ (soil moisture $=26 \%$ ). Again, $\omega_{s}$ was adjusted for a best fit. Results are shown in Figure 7. Clearly, the DIFF solution was source angle dependent (i.e., it did not embody the fundamental scattering nature of the soil). The NODIFF solution produces a more reasonable fit. Still, the hot spot is underestimated and the forward scattering is overestimated. Moreover, the backscatter at high VZA appears excessive. This may result from the nonindependence of soil roughness and phase function parameters during inversion. Specifically, both may 
Table 5. Mean Parameter Values With Standard Deviations Retrieved Through Model Inversions

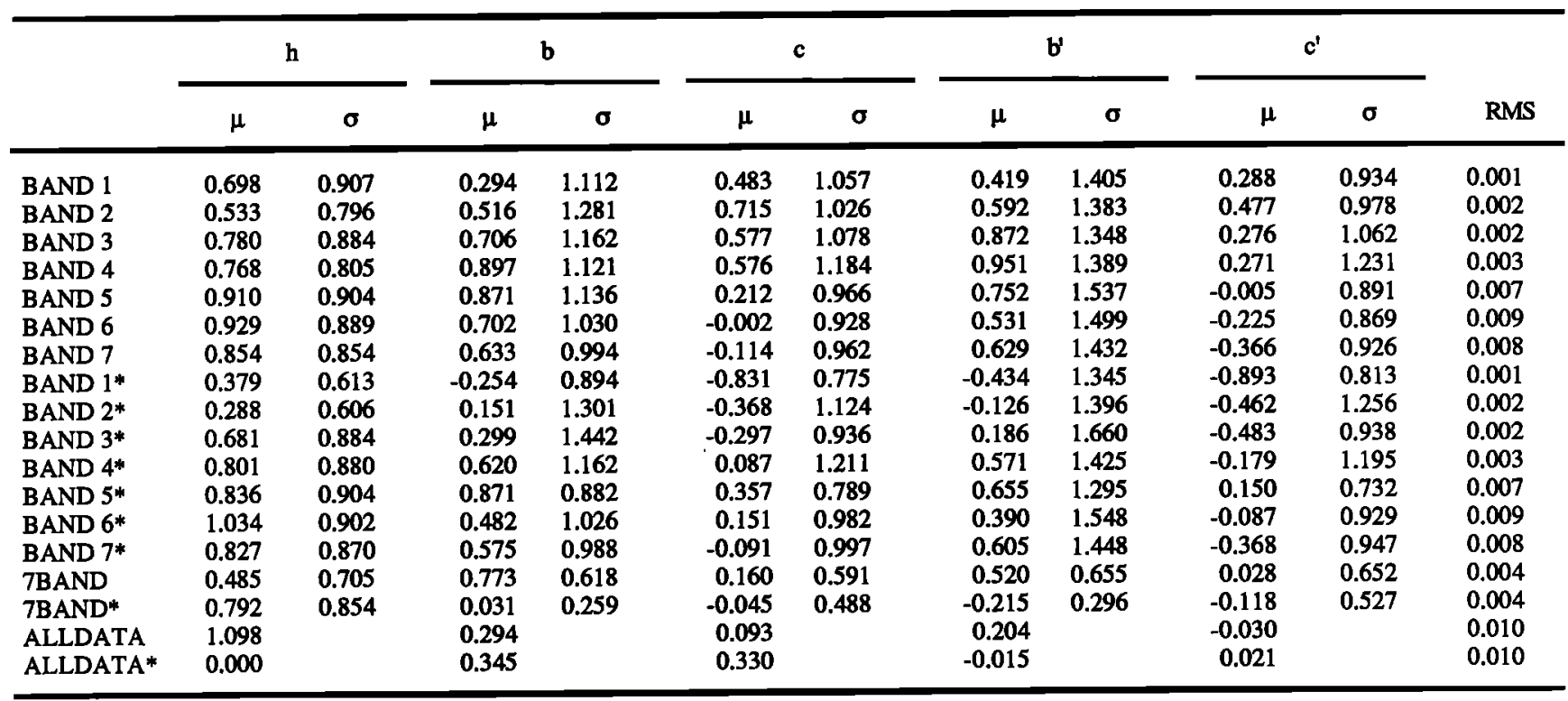

* Indicates the inversion was conducted with the diffuse irradiance parameterization.

produce increased retrosolar reflectance. Thus contrary to the findings of Jacquemoud et al. [1992] the comparisons here suggest the solutions depend on the solar angle or soil moisture.

\subsection{Inversions Using All Data (ALLDATA)}

Because of their dependence on solar angle the solutions above are unsatisfactory. Nevertheless, the results do suggest that inversions using more diverse data sets produce solutions with less dependence on sampling conditions. Following Jacquemoud et al. [1992], we included all samples (multiple bands, solar angles, and soil moisture levels) in a single inversion. This configuration would presumably allow better discrimination between scattering mechanisms (e.g., backscatter versus hot spot effects). Moreover, the minimization problem would be highly overdetermined, an advantageous situation given the limited MMR sampling.

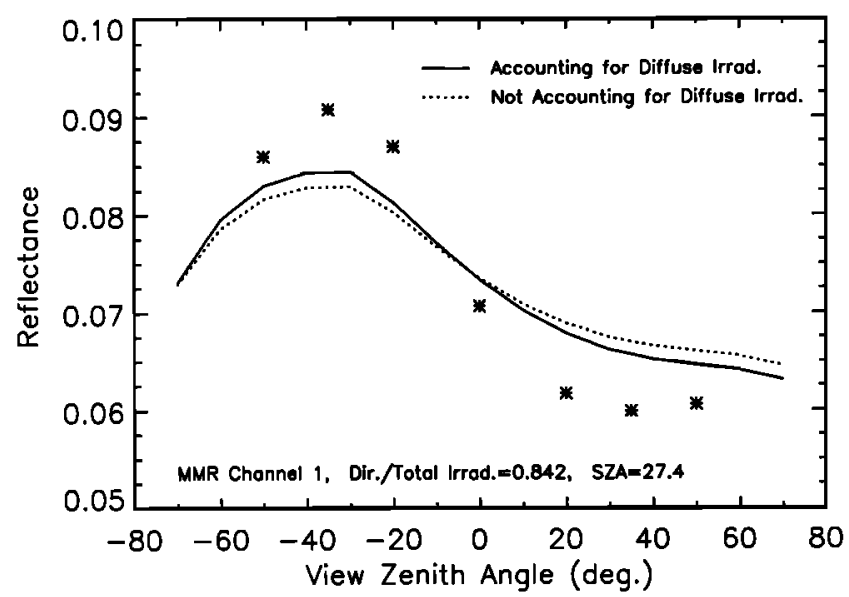

Figure 6. Fit of MMR band 1 data (asterisks) in the principal plane using band 7 solutions obtained with (without) the diffuse irradiance parameterization. The data and solutions were obtained at SZA = $27.4^{\circ}$.
To reduce the likelihood of a solar angle bias, some data sets were eliminated so that the resulting solar angle distribution would be reasonably even. Specifically, data gathered at three solar zenith angles per $10^{\circ}$ interval between $20^{\circ}$ and $60^{\circ}$ were used. Data sets with shaded samples were not used when possible. The result was a system of 84 data sets $(n=560$ unshaded samples) and 89 independent parameters $\left\{\omega_{s}, 1, \ldots\right.$, $\left.\omega_{\mathrm{s}, 84}, h, b, c, b^{\prime}, c^{\prime}\right\}(p)$. The inversion was initialized 30 times using randomly chosen parameter values and the clayey soil solution of Jacquemoud et al. [1992].

Inversions were first attempted using the diffuse irradiance approximation. After more than 100 hours of CPU time (Silicon Graphics Indigo), only 12 of the 30 inversions were completed. The lowest RMS solution is reported in Table 5. The RMS error is greater than those of the 7BAND and single band inversions. This reflects the more diverse data set used in the inversion. In contrast to the DIFF cases, all NODIFF cases

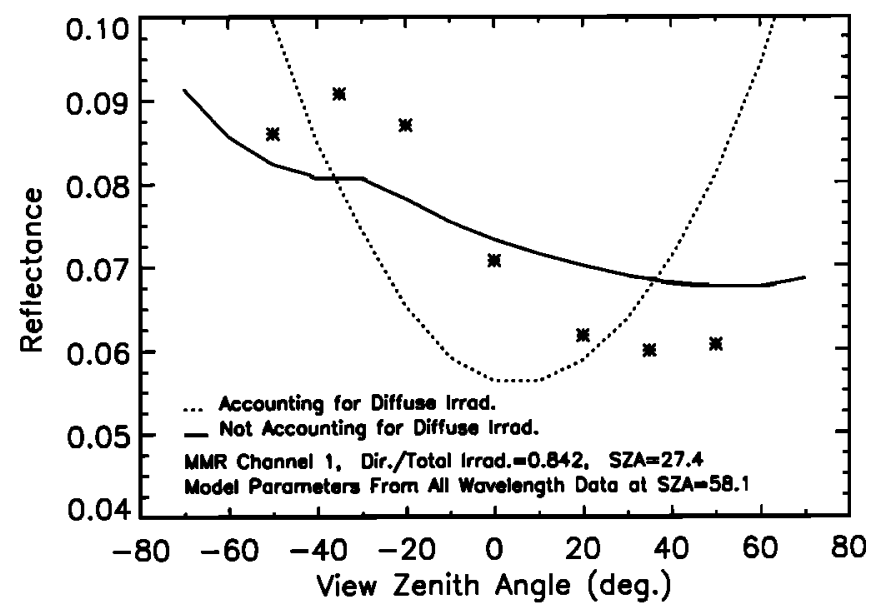

Figure 7. Fit of MMR band 1 data (asterisks) in the principal plane using 7BAND solutions obtained with(out) the diffuse irradiance parameterization. The data were obtained at SZA $=27.4^{\circ}$, and the solutions were obtained from data at SZA $=58.1^{\circ}$. 
converged. The solution resulting in the lowest RMS error is also shown in Table 5. The RMS error equals that obtained in the DIFF case.

To test the generality of the solutions, reflectance values were calculated for $27.4^{\circ}$ and $58.1^{\circ} \mathrm{SZAs}$ using both solutions (DIFF and NODIFF). Results are shown in Figures 8 (band 1, $S Z A=27.4^{\circ}$, soil moisture $-26 \%$ ) and 9 (band $7, S Z A-58.1^{\circ}$, soil moisture-36\%). The NODIFF solution again produced a better fit (Figure 8). While the hot spot is underestimated and the forward reflectance is overestimated, the maximum error is less than $10 \%$ relative. Comparing Figures 7 and 8 , it is also clear that the ALLDATA solution is an improvement over the 7BAND solution. Again, the DIFF solution does not exhibit a hot spot, although forward scattering is reasonably approximated. In Figure 9 the errors are significantly smaller for both solutions. The ALLDATA NODIFF fits in Figures 8 and 9 are representative of those for other bands, solar angles and moisture levels. A comparison of all measured and modeled reflectances (560 values) used in the ALLDATA NODIFF inversion is shown in Figure 10. The mean of the absolute values of errors is $0.006(3.5 \%)$. Based on these results, the NODIFF ALLDATA solution was used to specify soil reflectance in the coupled canopy model [Privette et al., 1995].

\subsection{Comments on the Diffuse Irradiance Approximation}

The usefulness of the diffuse irradiance approximation appears dependent on $\gamma$ and the solar angle. In Figure 8 the atmosphere is relatively transparent $(\gamma=0.842$ for band 1$)$. Although both ALLDATA solutions fit the data fairly well in the forward scattering region, only the NODIFF solution exhibits an obvious hot spot. The absence of a hot spot in the DIFF solution limits its usefulness in low SZA cases. Both solutions exhibit similar behavior for high SZAs, however (Figure 9). The DIFF inversions occassionally provided superior results, although this only seemed to occur under low- $\gamma$, high-SZA conditions (e.g., $\gamma=0.6$; $S Z A=58.1^{\circ}$ ).

Besides leading to inferior solutions in most cases, the diffuse approximation decreases the gradients of the merit function "surface" such that the optimization routine converges

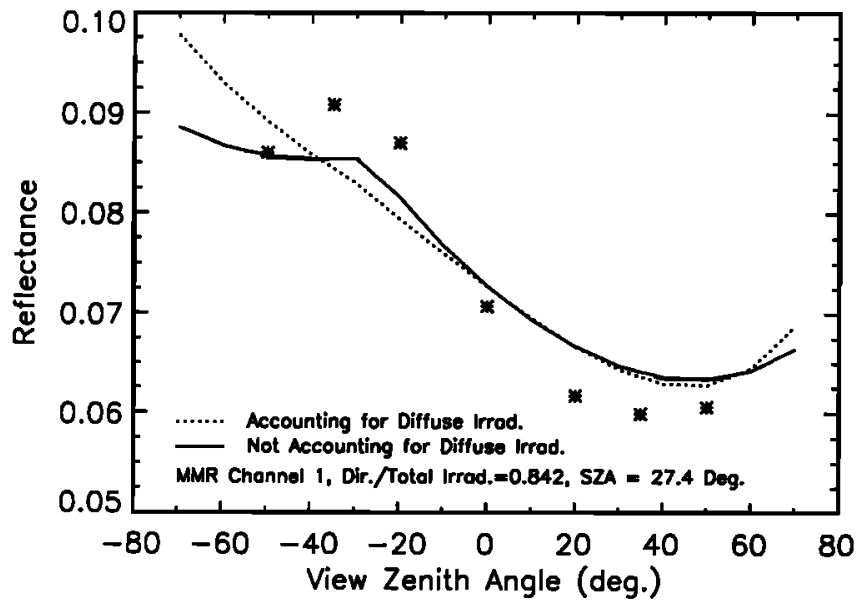

Figure 8. Fit of MMR band 1 data (asterisks) in the principal plane using ALLDATA solutions obtained with (without) the diffuse irradiance parameterization. The data were obtained at SZA $=27.4^{\circ}$, and the solutions were obtained over all SZA.

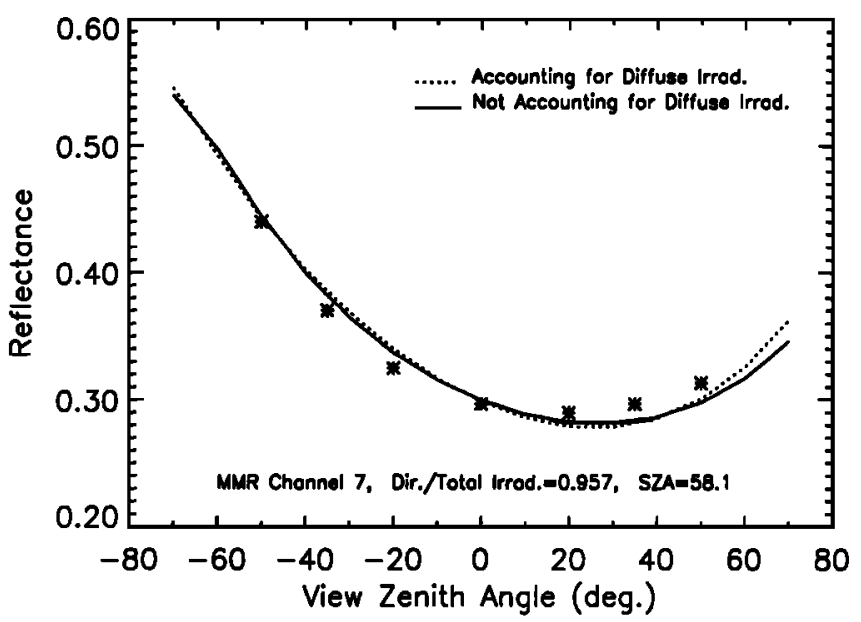

Figure 9. Same as Figure 8 except data were obtained in band 7 and at SZA $=58.1^{\circ}$.

relatively slowly. This follows from Figure 4 and the comments in section 4.6. If diffuse irradiance decreases the reflectance anisotropy, the model's sensitivity to soil parameters also decreases. This reduces the merit function range and the confidence in the inversion solution.

These results suggest that the neglect of our diffuse irradiance formulation during inversion leads to more general solutions. While this may not be true for hazy atmospheres, all data used in this study were gathered under clear skies. Thus in the analyses below the ALLDATA NODIFF solution is used exclusively.

\section{Model Validity in Directions Absent of Data}

The results above demonstrate that inversion solutions can depend on the solar angles of the inversion data. The solutions may likewise depend on the view angles. Indeed, because FIFE MMR sampling was restricted to seven view angles in the principal plane, the validity of the solutions was not ascertained for other directions (e.g., off the principal plane, at VZA $>50^{\circ}$ ). Thus in an effort to validate the ALLDATA solution, the effects of limited sampling geometries on inversion results are investigated below.

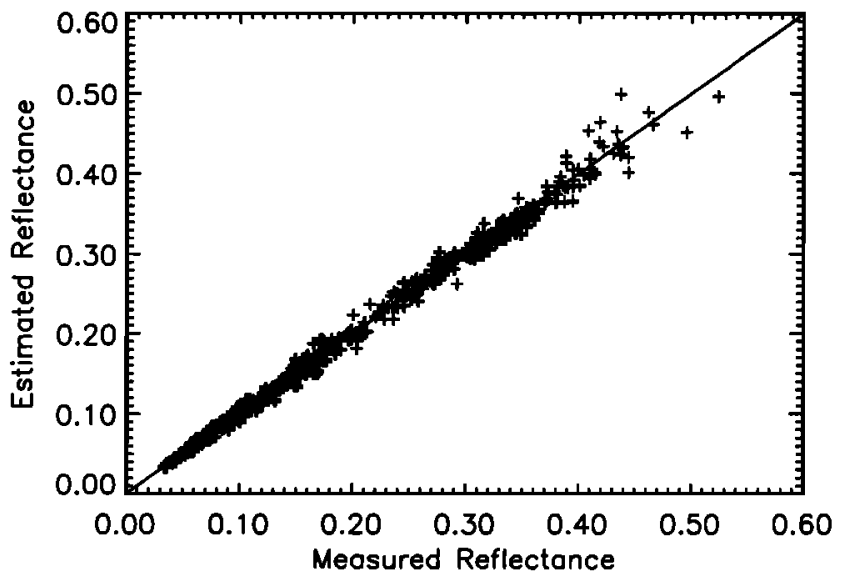

Figure 10. Comparison of measured data with model estimates from the ALLDATA solution. The 560 samples are from seven spectral bands, seven VZA, and 12 SZA. The 1-to-1 line is shown. 


\subsection{Comparisons With Solutions From Non- FIFE Data}

Assuming most soils scatter similarly, the validity of the ALLDATA solution can be investigated by comparing it with solutions found from non-FIFE data. Although Jacquemoud et al. [1992] utilized a comprehensive set of illumination and view angles, a comparison with their results is not conclusive since their measurements were made in a laboratory and thus do not contain effects of diffuse irradiance.

Data from Kimes et al. [1985b], however, were gathered over a plowed field. Moreover, these data were collected in multiple azimuthal planes and over a large range of VZAs (see Table 3). In the tests below, Kimes data gathered at three SZAs $\left(26^{\circ}, 30^{\circ}\right.$, and $\left.45^{\circ}\right)$ in the red $(0.58-0.68 \mu \mathrm{m})$ and NIR $(0.73-$ $1.1 \mu \mathrm{m})$ bands were used. For discussion purposes the ALLDATA solution found with the Kimes et al. [1985b] data is denoted "KIMES", while the ALLDATA MMR solution (see Table 5) and clayey soil solution from Jacquemoud et al. [1992] are denoted "MMR" and "JAC," respectively.

In this experiment, MMR data gathered at $27.4^{\circ}$ and $58.1^{\circ}$ SZA were fit with the KIMES and JAC solutions by adjusting $\omega_{s}$. All other parameters from the respective solutions remained fixed. The diffuse irradiance parameterization was only used with the JAC solution since it was determined from laboratory-measured data. Despite some differences in shape, all three solutions depict the general features in the data (Figures 11 and 12). All show a significant hot spot and relatively low forward scattering. Still, the KIMES and JAC solutions show greater anisotropy. Bum residue at site 916 may be responsible for the more Lambertian nature of the MMR data [F. Hall, personal communication, 1993].

Allowing that the three solutions produce similar behavior in the principal plane, the MMR solution off the principal plane can be assessed by again comparing the behavior of the three solutions. Orthogonal plane reflectance (band 1) for the same two solar angles is shown in Figure 13. Differences in the mean trends are obvious. Specifically, the MMR reflectance is nearly constant for SZA $=27.4^{\circ}$ while the KIMES and JAC solutions show decreasing reflectance with increasing

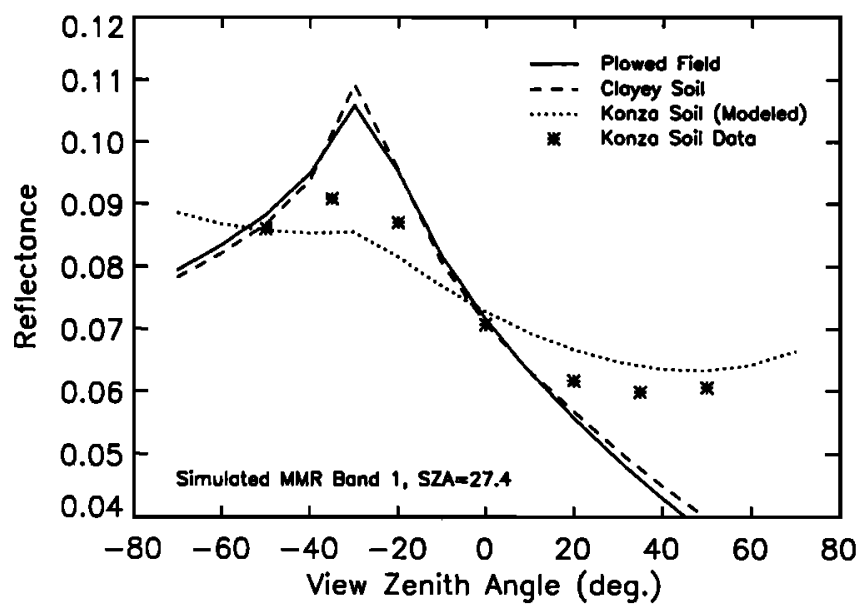

Figure 11. Comparison of solutions determined from different data sets to MMR band 1 data (asterisks) in the principal plane. The MMR data were obtained at SZA $=27.4^{\circ}$, and the solutions were obtained over all SZA.

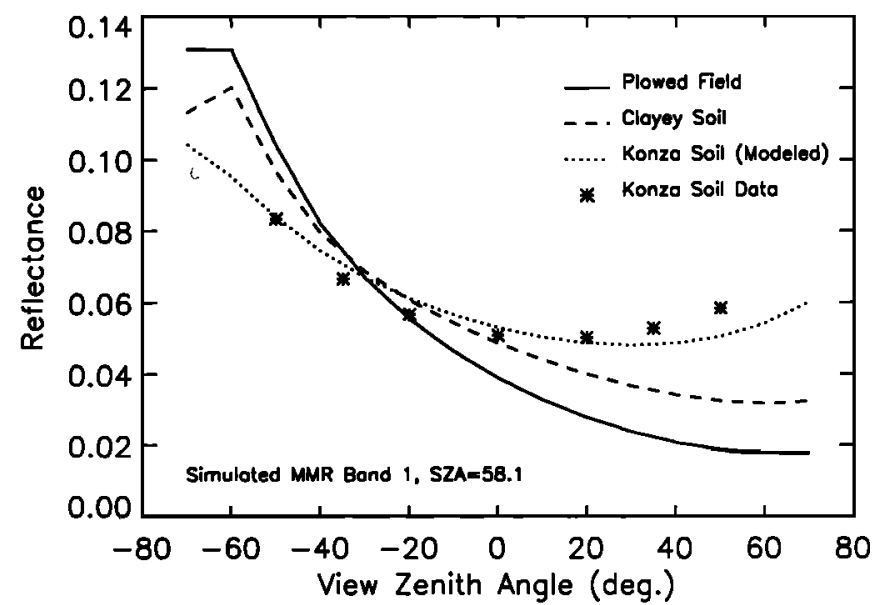

Figure 12. Same as Figure 11 except MMR data were obtained at SZA $=58.1^{\circ}$.

VZA. For SZA $-58.1^{\circ}$, the MMR solution produces increasing reflectance with VZA. The KIMES and JAC solutions, however, show nearly constant reflectance.

Further comparison is possible using reflectance data from an arid region (W. Van Leeuwen and A. Huete, unpublished data from HAPEX-SAHEL, 1993). The measured surfaces included crusty soil, dry and wet sand, and gravel. Although data at only one SZA per surface were available, the reflectance was sampled at multiple VZA in both the principal and the orthogonal planes (Table 3). The lack of high VZA data $\left(>50^{\circ}\right)$ is notable. The data were gathered in 46 spectral bands from 450 to $900 \mathrm{~nm}$. Again, ALLDATA solutions were fit to MMR band 1 data $\left(\right.$ SZA $=27.4^{\circ}$ ) by adjusting $\omega_{s}$. Principal plane fits are shown in Figure 14. Considering the vastly different surfaces, the estimates are reasonable. In particular, the crust, dry sand and gravel solutions show distinct hot spots. However, the dry sand solutions produce strong backscatter at high VZA whereas other solutions produce more modest backscatter. A decrease in forward scattering is exhibited by all solutions, yet at very high forward VZA, most of the solutions show increasing reflectance. The similarity to the MMR solution is no-

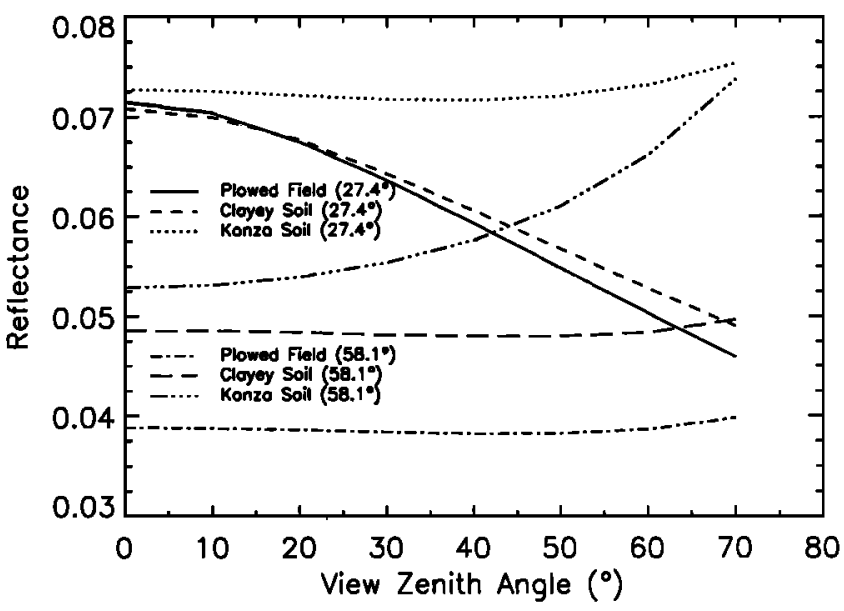

Figure 13. Comparison of solutions, determined from three different data sets, in the orthogonal plane. The solutions were plotted for solar zenith angles of $27.4^{\circ}$ and $58.1^{\circ}$. 


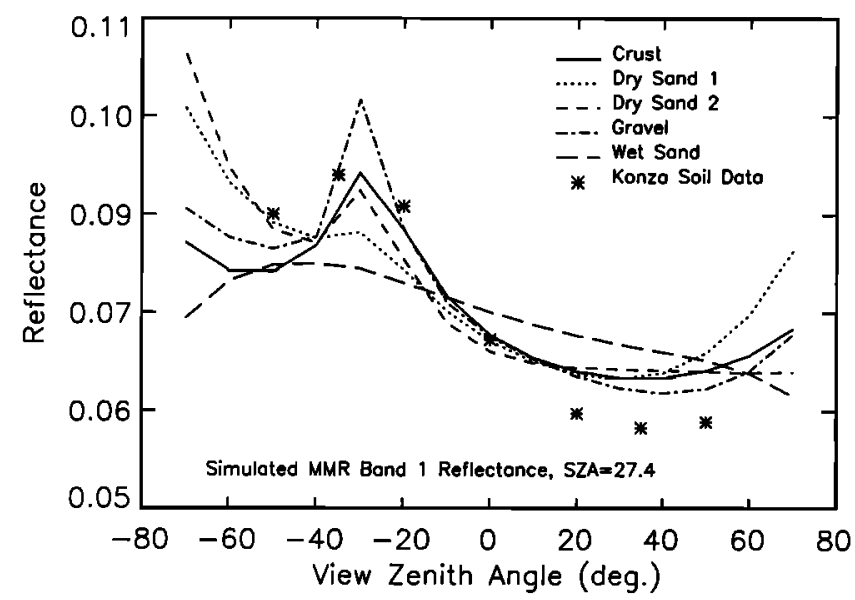

Figure 14. Comparison of solutions determined for arid surfaces to MMR band 1 data in the principal plane. The MMR data were obtained at $S Z A=27.4^{\circ}$, and the solutions were obtained at different SZA.

table (Figure 11), although the absence of samples at high VZA again prevents validation in this region. Finally, the decorrelation of the wet sand solution from the others is evident.

The orthogonal plane reflectance is shown in Figure 15. Most solutions show slightly decreasing reflectance to about $\mathrm{VZA}=45^{\circ}$, followed by sharp increases. This general behavior is similar to the MMR solution (cf. Figure 13; note differences in scales), although the reflectance increases at a greater rate for some arid soil solutions. Recall that the arid soils were not sampled at large VZAs $\left(>50^{\circ}\right.$ ), however. Thus the accuracy of the model reflectance at these angles is uncertain. The wet sand results again differ from those of the other surfaces.

\subsection{Solution Dependence on Sampling Scheme}

The above results suggest that the validity of the MMR solution is questionable for some directions (VZA $>50^{\circ}$ or in the orthogonal plane). However, some differences between the various solutions are due to surface differences. To estimate errors due strictly to MMR sampling geometry, the Kimes et al.

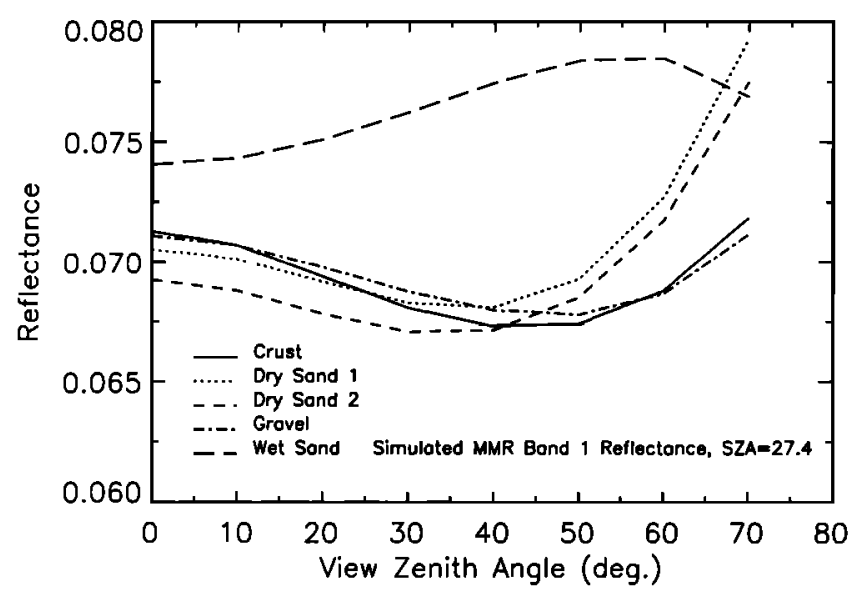

Figure 15. Comparison of solutions shown in Figure 14 but for the orthogonal plane. [1985b] data were subsampled to geometrically resemble MMR data. First, samples off the principal plane were eliminated. The reduced data sets contained 11 samples per band per solar angle. Samples suspected of shadow contamination were eliminated as before. Inversions were conducted using data from both bands and all SZA simultaneously (denoted "KIMES2"). Next, measurements at VZA > 50 were also eliminated. The resulting data sets (seven samples each) were used in independent inversions of each band and SZA (denoted "KIMES3").

Principal plane estimates of the Kimes data $\left(\mathrm{SZA}=30^{\circ}\right.$ ) are shown in Figure 16. The KIMES and KIMES2 solutions produce reasonable estimates over all VZA (the sample at $-30^{\circ}$ was not used since shadow contamination was suspected). The KIMES3 solution produces reasonable estimates, although it exhibits strong forward scattering at high VZA and appears to overestimate the hot spot. The similarity of the KIMES3 solution to the MMR and arid surface solutions (Figures 11 and 14, respectively; note differences in scales) at large VZA suggests systematic model behavior in these directions when no data are available.

Results in the orthogonal plane (Figure 17) differ significantly. Again, the KIMES solution produces a reasonable fit. However, the KIMES2 solution underestimates the data, the magnitude of error increases with VZA. Greater errors are exhibited by the KIMES3 solution which shows increasing reflectance with VZA. The similarity of the MMR, arid surface and KIMES3 solutions (Figures 13,15 , and 17, respectively; note differences in scales) further suggests that the orthogonal plane behavior of the MMR solution may have resulted from the limited sample geometries. This also supports the hypothesis, noted above, that inversions without data at high VZA produce solutions with large increases in principal plane reflectance in those regions.

\subsection{Discussion of Errors}

Several sources of errors may have affected the MMR results. The reported VZAs were accurate to $\pm 10^{\circ}$ azimuth and $\pm 2.0^{\circ}$ zenith. Also, as noted in the data set documentation, some variable cloud cover could have caused calibration

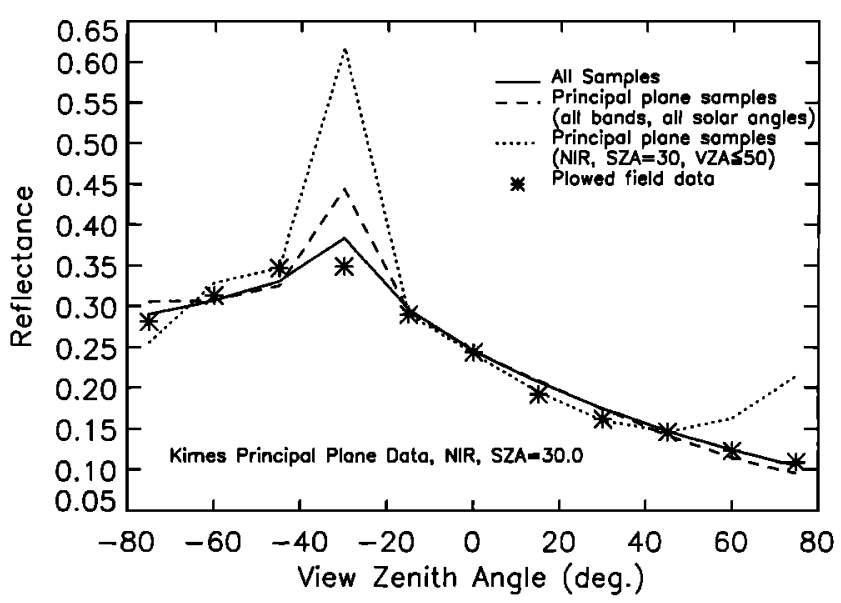

Figure 16. Comparison of solutions determined from plowed field data under different sampling schemes to plowed field data in the principal plane. The data were obtained at SZA $=30^{\circ}$, and the solutions were obtained at different SZA. 


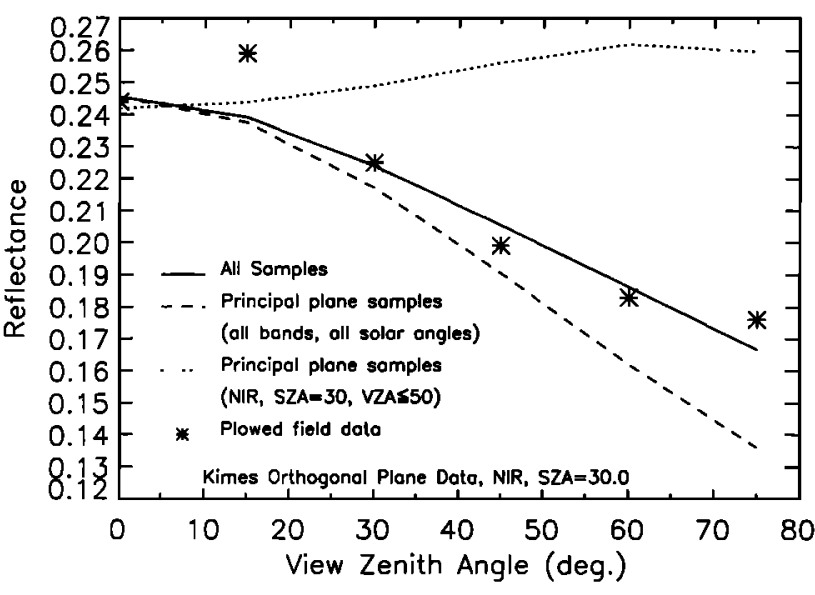

Figure 17. Same as Figure 16 but for the orthogonal plane.

differences since incoming radiation measurements were not simultaneous with surface measurements. The isotropy assumption in the diffuse irradiance formulation also introduces some inaccuracy, possibly more than the inaccuracy of neglecting diffuse irradiance.

As shown in section 6.2, the limited angular sampling with the MMR may have resulted in the largest errors. Not only might this affect the spectral, solar angle, and soil moisture invariance of the solutions, it may have led to unreliable reflectance estimates off the principal plane. Geometrically diverse data may be more important in inversions of semiphysically based models [e.g., Jacquemoud et al., 1992], since a physicallybased canopy model has been successfully inverted using just nine principal plane samples [Privette et al., 1994].

Finally, since directly shaded samples could only occur near the solar direction, the shadow filter may have biased the results. Specifically, nadir and forward scatter regions were better represented than the backscatter region. Thus forward scattering characteristics would preferentially influence the solutions. Furthermore, the trigonometric filter does not eliminate all shading effects since natural diffuse irradiance is incident from all directions.

\section{Conclusions}

This study describes important issues in specifying soil reflectance for vegetation bidirectional reflectance models. For low solar and view zenith angles, only canopies of about LAI $>8$ can be considered "dense" semi-infinite mediums. A Lambertian soil was found to provide a poor representation of anisotropic soil reflectance at lower LAI conditions. The errors were greatest in the backscattering region, where a Lambertian soil results in an underestimation of canopy reflectance. Overestimation of forward scattering may also result albeit to a lesser extent.

Simulations also showed that backscattering decreases and forward scattering increases as the ratio of direct to total irradiance $(\gamma)$ decreases. Hence soils appear more Lambertian as diffuse irradiance increases. Although an isotropic diffuse irradiance formulation was added to the soil model of Jacquemoud et al. [1992], its usefulness remains questionable since it resulted in larger inversion times and marginal improvements.
To develop a suitable lower boundary condition for a canopy reflectance model, the soil model was inverted using ground-based radiometer data from FIFE. Results showed that comprehensive sampling (data from all available spectral bands, solar angles, and soil moisture levels) was necessary to provide a generally applicable solution. Single-band inversions did not provide spectrally independent solutions and multiple-band inversions (at a single solar angle and moisture level) did not produce solutions applicable to other solar angles and moisture levels. The inversion of a canopy reflectance model, using results from this study, is reported elsewhere [Privette et al., 1995].

Finally, the need for angularly diverse samples in the inversion of the reflectance model was shown. Specifically, soil model reflectance in the orthogonal plane can be inaccurate when model parameters are determined exclusively from principal plane data. This problem has not been observed with a physically based canopy model [Privette et al., 1994]. Thus it appears that inversions with less rigorous reflectance models may require more cautiously compiled data sets. This is important given the planned EOS multi-angle imaging spectroradiometer (MISR) [Diner et al., 1989] which, for targets in its ground track, will scan one azimuthal plane per pass.

Acknowledgments. Data used in this study were collected by B. L. Blad, E. A. Walter-Shea, C. J. Hays, and M. A. Mesarch (MMR soil reflectance); Wilfried Brutsaert and his team (radiosonde); Robert Fraser and his team (ozone and optical depth); Dan Kimes, Wim Van Leeuwen, and Alfredo Huete (soil reflectance); Brian Markham (MMR band sensitivity); and the staff from the Kansas State Evapotranspiration Laboratory (soil moisture). Richard Slonaker provided a water vapor algorithm for the radiosonde data. Stephane Jacquemoud provided additional information on the soil model and Jim McManus at FIS assisted with numerous data set issues. These contributions are gratefully acknowledged. A significant portion of this work was completed at Université Blaise Pascal in France. RMB and JLP acknowledge the generosity and support of the Laboratoire de Metéorologie Physique in Clermont-Ferrand. JLP was sponsored by the U.S. Department of Energy under appointment to the Graduate Fellowships for Global Change, administered by the Oak Ridge Institute for Science and Education. Partial support was also provided by NASA's EOS/IDS program (R. Dickinson, P.I.). RBM is a University of Maryland Research Associate.

\section{References}

Cierniewski, J., A model for soil surface roughness influence on the spectral response of bare soils in the visible and near infared range, Remote Sens. Environ., 23, 97-115, 1987.

Cooper, K. D., and J. A. Smith, A Monte-Carlo reflectance model for soil surfaces with three-dimensional structure, IEEE Trans. Geosci. Remote Sens., GE-23, 668-673, 1985.

Deering, D. W., E. M. Middleton, J. R. Irons, B. L. Blad, E. A. WalterShea, C. J. Hays, C. Walthall, T. F. Eck, S. P. Ahmad, and B. P. Banerjee, Prairie grassland bidirectional reflectances measured by different instruments at the FIFE site, J. Geophys. Res., 97, 18,887$18,903,1992$.

Dickinson, R. E., B. Pinty, and M. M. Verstraete, Relating surface albedos in GCMs to remotely sensed data, Agric. Meteorol., 32, 109-131, 1990.

Diner, D. J., et al., A multi-angle imaging spectroradiometer for geophysical and climatological research from EOS, IEEE Trans. Geosci. Remote Sens., GE-27, 200-214, 1989.

Eaton, F. D., and I. Dirmhirn, Reflected irradiance indicatrices of natural surfaces and their effect on albedo, Appl. Opt., 18, 994-1003, 1979.

Goel, N. S., Models of vegetation canopy reflectance and their use in estimation of biophysical parameters from reflectance data, Remote Sens. Rev., 4, 1-213, 1988.

Goel, N. S., and R. L. Thompson, Inversion of vegetation canopy reflectance models for estimating agronomic variables, IV, Total in- 
version of the SAIL model, Remote Sens. Environ., 15, 237-253, 1984.

Hapke, B., Bidirectional reflectance spectroscopy, 1, Theory, $J$. Geophys. Res., 86, 3039-3054, 1981.

Iaquinta, J., and B. Pinty, Adaptation of a bidirectional reflectance model including the hot spot to an optically thin canopy, in Physical Measurements and Signatures in Remote Sensing, International Society of Photogrammetry and Remote Sensing, Val D'Isère, France, 1994

Irons, J. R., G. Campbell, J. M. Norman, D. W. Graham, and W. M. Kovalick, Prediction and measurement of soil bidirectional reflectance, IEEE Trans. Geosci. Remote Sens., GE-30, 249-260, 1992.

Jacquemoud, S., F. Baret, and J. F. Hanocq, Modeling spectral and bidirectional soil reflectance, Remote Sens. Environ., 41, 123-132, 1992.

Kimes, D. S., Dynamics of directional reflectance factor distributions for vegetation canopies, Appl. Opt.., 22, 1364-1372, 1983.

Kimes, D. S. and J. Kirchner, Radiative transfer model for heterogeneous 3D scenes, Appl. Opt., 21, 4112-4118, 1982.

Kimes, D. S., J. A. Smith, and K. J. Ranson, Vegetation reflectance measurements as a function of solar zenith angle, Photogramm. Eng. Remote Sens., 46, 1563-1573, 1980.

Kimes, D. S., J. M. Norman, and C. L. Walthall, Modeling the radiant transfers of sparse vegetation canopies, IEEE Trans. Geosci. Remote Sens., GE-23, 695-704, 1985a.

Kimes, D. S., W. W. Newcomb, C. J. Tucker, I. S. Zonneveld, W. Van Wijngaarden, J. de Leeuw, J., and G. F. Epema, Directional reflectance factor distributions for cover types of Northern Africa, Remote Sens. Environ., 18, 1-19, 1985b.

Myneni, R. B., V. P. Gutschick, G. Asrar, and E. T. Kanemasu, Photon transport in vegetation canopies with anisotropic scattering, I-IV, Agric. Meteorol., 42, 1-40, 87-120, 1988.

Myneni, R. B., G, Asrar, and F. G. Hall, A three dimensional radiative transfer model for optical remote sensing of vegetated land surfaces, Remote Sens. Environ., 41, 85-103, 1992.

Norman, J. M., J. M. Welles, and E. A. Walter, Contrasts among bidirectional reflectance of leaves, canopies and soils, IEEE Trans. Geosci. Remote Sens., GE-23, 659-667, 1985.

Numerical Algorithms Group (NAG), The NAG Fortran Library, Mark 14, vol. 3, NAG Incorporated, Downers Grove, Ill., 1990.

Pinty, B., M. M. Verstraete, and R. E. Dickinson, A physical model for predicting bidirectional reflectances over bare soil, Remote Sens. Environ., 27, 273-288, 1989.

Privette, J. L., R. B. Myneni, C. J. Tucker, and W. J. Emery, Invertibility of a 1-D discrete ordinates canopy reflectance model, Remote Sens. Environ., 48, 89-105, 1994.
Privette, J. L., R. B. Myneni, W. J. Emery, and F. G. Hall, Optimal sampling conditions for estimating grassland parameters via reflectance model inversions, IEEE Trans. Geosci. Remote Sens., in press, 1995.

Rao, V. R., E. J. Brach, and A. R. Mack, Bidirectional reflectance of crops and the soil contribution, Remote Sens. Environ., 8, 115-125, 1979.

Richardson, A. J., C. L. Wiegand, H. W. Gausman, J. A. Cuellar, and A. H. Gerberman, Plant, soil and shadow reflectance components of row crops, Photogramm. Eng. Remote Sens., 41, 1401-1407, 1975.

Ross, J. K., The Radiation Regime and Architecture of Plant Stands, 391 pp., W. Junk, The Hague, Netherlands, 1981.

Sellers, P. J., F. G. Hall, G. Asrar, D. E. Strebel, and R. E. Murphy, The first ISLSCP field experiment (FIFE), Bull. Am. Meteorol. Soc., 69 22-27, 1988.

Tanré, D., C. Deroo, P. Duhaut, M. Herman, J. J. Morcrette, J. Perbos, and $P$. Y. Deschamps, Description of a computer code to simulate the satellite signal in the solar spectrum: The 5S code, Int. J. Remote Sens., $11,659-668,1990$.

Verhoef, W., Light scattering by leaf layers with application to canopy reflectance modeling: The SAIL model, Remote Sens. Environ., 16, 125-141, 1984.

Walter-Shea, E. A., B. L. Blad, C. J. Hays, M. A. Mesarch, D. W. Deering, and E. M. Middleton, Biophysical properties affecting vegetative canopy reflectance and absorbed photosynthetically active radiation at the FIFE site, J. Geophys. Res., 97, 18,925-18,934, 1992.

Walthall, C. L., J. M. Norman, J. M. Welles, G. Campbell, and B. Blad Simple equation to approximate the bidirectional reflectance from vegetative canopies and bare soil surfaces, Appl. Opt., 24, 383-387, 1985.

W. J. Emery and J. L. Privette (corresponding author), CB 431, Department of Aerospace Engineering Sciences, University of Colorado, Boulder, CO 80309. (email:emery@frodo.colorado.edu; privette@frodo.colorado.edu)

R. B. Myneni, Biospheric Sciences Branch, Mail Code 923, NASA Goddard Space Flight Center, Greenbelt, MD 20771. (email: myneni@scarpia.gsfc.nasa.gov)

B. Pinty, Laboratoire de Météorologie Physique, URA 267/CNRS Université Blaise Pascal, F-63177 Aubière, France. (email: pinty@opgc.univ-bpclermont.fr)

(Received April 4, 1994; revised February 8, 1995; accepted February 8, 1995.) 